\title{
Cultural Identities and Consumer Goods Notes on the Classificatory Vocation of Advertising
}

\author{
Bruna Aucar \\ Adjunct Professor of the Department of Social Communication at the Pontifical Catholic \\ University of Rio de Janeiro \\ (PUC-Rio). $\mathrm{PhD}$ in Social Communication \\ PUC-Rio. \\ Everardo Rocha \\ Full Professor of the Department of Social Communication at PUC-Rio. \\ $\mathrm{PhD}$ in Social Anthropology \\ National Museum/UFRJ. \\ Pontifical Catholic University of Rio de Janeiro
}

\begin{abstract}
This work discusses advertising narratives as important classificatory operators in modern-contemporary culture. Classification practices are central in defining the organization of diverse societies. Advertising, as a classification system, promotes meaningful bonds between individuals and consumer goods that shape identities dislocated from tradition and establish new parameters for social exchange. Media messages amplify ads and turn consumption into a phenomenon that not only defines the meaning of goods, butarranges our social identities and tangible experiences.
\end{abstract}

Keywords: Advertising; Consumption; Classification; Lévi-Strauss.

\section{Ads and totems}

This work proposes a theoretical discussion on advertising as a mechanism that connects important cultural meanings in modern-contemporary life by triggering a complex classification system of products and services, on the one hand, and social identities and subjectivities, on the other. Lévi-Strauss's study $(1962 / 1964,1962 / 2020)$ on totemism showed, among other things, that classification systems are present in diverse societies as a central practice for establishing collective meanings and codes of conduct. In his classic works Le Totémisme Aujourd'Hui and La Pensée Sauvage, both published in 1962, the author argues that human groups have the impulse to classify and attribute order to elements of their surrounding world, conceiving relationships, differences and oppositions between them.

According to Lévi-Strauss, totemism is a classification system through which cultures relate elements they define as "natural" to those they distinguish as "cultural". Its central idea is the articulation of differences and similarities between the human and non-human spheres. The definition of natureemerges from the logic of totemic classification, which is based on a relational dynamic and expresses itself in specific ways in different cultures. Lévi-Strauss's (1962/1964) famous observation that natural species are not known because they are "good to eat" but because they are "good tothink" highlights the primacy of speculative thinking over biological necessity and of cultural meanings over raw matter. Within a given cultural order, totemic systems convert messages andengender intellectual associations that constitute patterns. The contents of the "natural" sphere are relative to such culturally determined arrangements. In this sense, nature is best understood as the sphere of what is different from and alien to the human dimension.

Based on Lévi-Strauss's studies on totemism, Author (1985) argues that media narratives - specially, advertising - are like totemic operators that convert messages between production and consumption. Advertising narratives give sense to production, classifying its outputs in terms of needs and desires in the sphere of consumption, the social arena where these meanings are performed. Regarded as a process that alienates human dimension (Marx, 1867/1977; Marx \& Engels, 1848/1992), production is a sphere similar to "nature" and has to be infused with cultural meanings to fulfill its destiny as consumption. Advertising and other media narratives convert production into language and expression of desires, dreams, needs, life styles, and so forth, turning impersonal and lifeless stuff into relevant goods, familiarto their publics. By virtue of the meanings that these narratives attach to things, serialized and anonymous production becomes a world of goods in which social representations rise, imagination is legitimized and social agents create relationships. 
In Lévi-Strauss's (1962/1964) words, our emotions are conditioned to what is permissible and requiredas per rules of custom: (...) each man feels as a function of the way in which he is permitted or obliged to act. Customs are given as external norms before giving rise to internal sentiments, and these non sentient norms determine the sentiments of individuals as well as the circumstances in which they may, or must, be displayed. (p. 70)

In modern-contemporary society, consumption is a code that translates external norms into products and services that become a part of our social identities and subjectivities. Consumption expresses distances, connections, roles, positions, affects, feelings, material and subjective hierarchies. Advertising narratives construct and circulate meanings that provide parameters of distances and relationships between subjects, object recommendations, sensibility models, power expressions, body techniques and identity perceptions for each and every one. To promote consumption, advertising creates and projects concepts of beauty, personal fulfillment, status, well-being, health, happiness, and so on.

Misfortunes, pains or frustrations have no place in ads. The world designed by advertising has solutions for anything, guarantees the pleasure principle and fulfills desires. Life in ads is made of cozy homes, engaging work and peaceful sleep; complaints, discomfort and sadness are left out (Author, 1985). Advertising nurtures the idea of pleasure spread by mass culture, developing themes of personal fulfillment, love, seduction and magic in imagery and romanced information (Morin, 1962). Therefore, language enchantments, the allure of images, the dissemination of unreality and representations of the contemporary ideal of happiness are devices used in the construction of discourses that affect innermost desires and place consumption as a source of subjective fulfillment. Roy Wagner (1975) considers advertising as a phenomenon that manifests a kind of magical thinking in modern-contemporary societies. Likewise, Roberto DaMatta (1985) emphasizes the importance of investigations on the invisible magical structures that underlie capitalism. Ads take consumers to a fantasy universe that reimagines everyday life through products endowedwith names, personalities, origins and magical properties.

\section{The place of objects}

Modern-contemporary culture invests in the intersecting relations between humans and artifacts in the construction of identities. Objects tell life histories. They are materiality transformed into archives that register, cultivate and preserve the memorial value of past experiences. On the other hand, objects generate new meanings and values, shape who we intend to become and the social image we wish to project (McCracken, 1988). Objects celebrate collective dates Christmas, Mother's Day, Valentine's Day, etc. - and private occasions - birthdays, weddings, and commencements. Generally, important moments of personal and professional trajectories are marked by rites to which correspond objects that symbolize the passage from a given position to another. Wedding bands identify people who are married. Diplomas on the wall attest formal education and titles. A toy celebrates another year in a child's life.

The presence of artifacts that support and give visibility to ritual practices reinforces the notion of consumption as a phenomenon that elicits meaningful bonds and sheds light on the interactions that happen between material culture and the construction of subjectivities. Social groups celebrate events marked as special or that escape routine. These can be carnivals or tributes, religious or secular celebrations, official or unofficial parties. In tribal societies, magical or religious elements articulate meanings that associate ritual to the sacred sphere that governs and organizes collective experience in these cultures (DaMatta, 2011).Rituals have transformative and classificatory potentials, restating moral and ethical values, granting authority and legitimacy to the people that assume certain positions and roles in a social structure (Trindade \& Perez, 2014). Furthermore, rites express the intangible dimension of relationships. Through recurrence, ritualization offers a feel of stability and emotional comfort to social groups. Formality and repetition are characteristics that define ritual experience. By knowing the sequence of acts and stages of a rite, participants develop the sense of belonging to a community. Order and tradition inspire the continuation of collective values.

Relations of exchange, possession and use of artifacts, as well as attachment to or detachment from them, are ritual processes (Douglas \& Isherwood, 1979; Miller, 1998, 2008).Transfers of meanings from social values to goods and from goods to people guide ritual practices. In a consumer society, ritual is part of a cultural system expressed, reproduced and recreated in advertising. The internal discourse of ads highlights elements of reality to rearrange and connect them in particular ways, making rites out of these combinations. The act of purchase implies the transposition from one thing to another, the encounter of consumers with ads and the transfer of meaning from the product to the subject's identity.

McKendrick, Brewer and Plumb (1982) observed that the link between youths and the objects that made up their identities changed in the passage to modernity in England. Around the eighteenth century, new generations became ever less interested in inheriting artifacts from their ancestors. 
Things that had meanings related to family lineage and memory began to lose their appeal due to rapidly changing market offers and persuasion mechanisms such as advertising. Families became less engaged in maintaining heirlooms and more open to acquiring new items and renovating their emblems of distinction. The family organization started choosing from the plurality of available products those with the ensemble of symbols that would better represent them in society at a given moment (McKendrick, Brewer \& Plumb, 1982).Every change in circumstances corresponded to new meanings, status and sense of belonging. Also, collective institutions became weaker as individualism grew stronger. The emphasis on autonomous individuals over family and community propelled consumption, and every purchase act became an opportunity to redefine the concept of oneself. Collective life goals declined while the individual emerged as the focus of the system of consumption and its messages (McKendrick, Brewer and Plumb, 1982).

Ephemeral consumption in contemporary capitalism expands the range of possibilities for the constitution and maintenance of identities. In that context, relations with previous generations through heirlooms are less relevant then new bonds with the world of goods and freedom choice. Identities are thought of as blank canvases that individuals may paint with the contents they so desire, erase and redo. Objects have a central role in that process of writing the self and in the variety of definitions for social identities. As McCracken (1988) explains:

For the old system of family and inheritance, the movement of goods from one generation to the next was an important method of preserving the corporation, insuring its continuity, relaying its values, and of bringing each successive generation into the lineage. (...) For the new system, goods are equally important. They are the sources to which families and their individuals turn for the meaning that no longer descends to them from lineage. These goods are useful in this manner only because they are products of a meaning-producing system and perpetually revised for new social circumstances. The currency of their meaning makes them quite useless to successive generations. (p. 51)

Guided by new tastes and options, autonomous consumers surrender themselves to the incessant process of acquiring goods. Individualism is one of the pillars that sustains capitalism. Its emergence as a structuring value is one of the transformations that characterize Western modernity, and resulted in the shift of the nucleus of consumption from family to individual (McCracken, 1988). In this sense, the precedence of individualism over holism was a significant contribution for the expansion of modern consumption. Independent subjects are converted into consumers with ability to choose on their own terms. From the perspective of the individual, the needs of conspicuous consumption are more immediate and less dependent on the accumulated status of the family clan. The social competition that this change multiplies and fragments is a major drive for advertising, increasing the demand for time and resources dedicated to consumption. A significant amount of information became necessary for social actors to make their choices with confidence. New expressions of individualism both engendered new patterns of consumption and were governed by them (McCracken, 1988).

Transformations in the collective mindset, politics, social institutions and economic conditions of Western societies, at least since the Industrial Revolution, contributed to the development of new tastes, preferences and shopping habits. Western culture became ever more conditioned and integrated by goods and consumer practices that attribute meanings to subjectivities, sensibilities and bodies. Fashion dynamics intensified with the acceleration of production and product turnover in the market, besides the involvement of commerce and media professionals that invented new styles and made previous ones obsolete through persuasion techniques (McCracken, 2003). Goods were no longer committed to longevity or to the family group itself. Prescription of the new is established and becomes an incessant addiction (Morin,1962). Conspicuous consumption gradually replaces the leisure of nobles as a sign of distinction (Veblen, 1899/2007).

Georg Simmel (1904) was among the pioneers to reflect on the phenomenon of fashion as part of the broader cultural transformations that characterize modernity. In his article, the author highlighted the paradox of consumer practices that lead both to social equalization, on the one hand, and social differentiation, on the other. The author describes a process that some refer to as "trickled-down" effect (McCracken, 1988). According to Simmel (1904), fashion is a form of imitation that can unite members of a social class while segregating them from others. Elites initiate a fashion to distinguish themselves, but are soon followed by members of other social strata that imitate them. Since imitation eliminates external distinctions, elites abandon the current fashion for a newer one, reestablishing differentiation in a move that quickens as wealth increases. In Simmel's view, upper classes would change preferences and seek novelties as soon as lower classes incorporated their consumer practices in an endless cycle of renovation. 
Nobility's loss of certain symbols allowed the emergence of representations of status in other social strata. Williams (1982) indicates that, in the decades following the French Revolution, the bourgeoisie began imitating courtly standards of consumption. Luxury moved out of noble households to the marketplace, shifting from private to conspicuous consumption. Aristocracy lost not just political authority, but also symbolic (William, 1982). Soon former nobles found themselves subordinate to the incessant principle of fashion and the power of capital. Social mobility and prestige were no longer tied to generational legacy and could be obtained through consumption. Money could be converted into status almost immediately. Consumption provided a new configuration, transitory and unstable, with classifications that changed and were built on each move in the social arena and in history.

In modern-contemporary culture, advertising is a classification system capable of both creating choices for new generations and handling all the variables at play. To classify is to impose standards, order, a reference model. Classification regulates the senses, establishes symbolic borders, be them walls or bridges that translate and guide practices. Resulting from collective constructions and negotiations, classification systems legitimize interpretations of the world. The exercise of classification establishes the right and the wrong, the acceptable and the prohibited, in specific ways in different cultures.

\section{The classification system of advertising}

Inspired by Lévi-Strauss's work on totemism (1962/1964, 1962/2020), the idea that advertising narratives triggers and/or raises a classification system in modern-contemporary culture comes from the observation of continuous movements of similarities and differences, the dynamic positioning of elements that impose hierarchies. Classification marks border lines that help us understand the map of culture and locate ourselves in it.

Advertising narratives, produced and circulated by different media, give space, appeal and visibility to values already present in the collective imagination, as well as articulate unusual meanings that will gradually be incorporated into modes of living. The classificatory vocation of advertising derives from exchanges and intersections between media and social agents, especially, with the subjectivation of mass culture values and their permeation in social experiences (Morin, 1962).Advertising narratives confer cultural meanings to goods, indicate the spaces they should occupy, and show how they should be used. In doing so, ads connect goods to the habits of diverse types of social actors. Thus, ads are like guides that teach about material utilities and, above all, about established social rules through the consumption of goods produced in large scale (Author, 1995).

According to Baudrillard (1970/1998), consumers are not after the object itself nor its use-value, but want the signs that manipulate the object and distinguish individuals either by connecting them to an ideal social group or by differentiating them in a superior position within the hierarchy of that group. The analysis of the advertising system isa window through which we can observe the meaningful links established between objects and consumers with the mediation of brands and ads. Consumption is an act of communicating, exchanging and sharing meanings, a ritual that activates differential values for social action strategies based on the classifications of goods and people.

Campbell (1987) argues there is no single absolute system that can handle the meanings that objects may have in a given culture and historical moment. Artifacts may take on multiple meanings in different contexts. Moreover, the communicative dimension of the object is only complete if the interlocutor is able to decipher its cultural significance. If not, the interlocutor cannot infer the object's meaning or ends up interpreting it in another way. Messages can take on different interpretive connotations, depending on the recipient's view. Hence, the information conveyed can be misunderstood or deciphered in an unintended way.

Advertising narrative is a social discourse that seeks to stabilize and sustain floating meanings. Its purpose is to consolidate signs in certain contexts, creating a common language for the interpretation of reality through consumption.

The classification system of advertising interrelates people and objects, triggering meanings based on cultural categories that set malleable parameters. Ads introduce in certain contexts ideas that endure for short time spans, since meanings need to be constantly reworked and recreated to keep the cycle of the consumption system alive. The historical dimension is essential for the transformation of distinction criteria. New classifications and value hierarchies are built over time and can be examined through ads.

Media investment on certain narrative lines is intimately related to the interests of sponsors and their cultural-historical context. For instance, during the 1960s and 1970s in the United States and in 1980s Brazil, advertising vigorously promoted cigarette consumption as symbol for prestige, group belonging, professional and personal success. 
Memorable Brazilian ads for the Hollywood cigarette brand translated the spirit of the time and portrayed a life style that many aspired then. In most of these commercials, beautiful and athletic youths appeared practicing radical sports in gorgeous places to the sound of famous songs.

The tobacco industry was in a rising trajectory in the Latin American country. Besides influencing the ideas and practices of an entire generation, tobacco companies were among the major sponsors of Brazilian mass media, investing millions in advertising. In telenovelas of the 1980s, successful characters would often appear with a cigarette in hand. In the following decade, however, perceptions about smoking began to change in a negative sense in Brazil and many parts of the world. On July 15, 1996, National Law 9,294/96 banned ads for tobacco-based products in the media. Cigarette advertising was restricted to placards and signs inside the point of sale. ${ }^{1}$ Furthermore, tobacco companies were prohibited from sponsoring cultural and sporting activities. That market segment has since been occupied by the big beer companies, despite the restriction on broadcast television commercials for alcoholic beverages before 21 hours. Though alcohol consumption is a major public health issue in the world, there are no advertising mechanisms to discourage the population from drinking.

Values that were emphasized at one point give way to arguments that are totally opposite at another. Increase in population numbers and in life expectancy stirred public debate towards health and environmental concerns, which were incorporated by advertising narratives. In that process, cigarettes were cast as villains against the new social models. A United Nations report predicts that world population, currently at 7.7 billion, will reach 11 billion by the end of the twenty-first century (United Nations, 2019). While in the year 2000 life expectancy was around 66.5 years old, a child born in 2016 can expect to live for 72 years (G1, 2019). Health and well-being became ideological stars and indispensable goals in processes that have consumption as a guiding thread (Author, 2012). Advertising choices reproduce and sustain these maps of socio-cultural orientations that permeate contemporary life.

Body care, regular exercise, new techniques and medications to control anxieties and depression, healthy eating, responsible use of natural resources, attention to environmental concerns were some of the themes that gained interest and, above all, market space since the 1990s. Along with shifts in public debate come other configurations of urban space and related consumption habits, such as the proliferation of gyms, record numbers of plastic surgery, ${ }^{2}$ rise of organic food fairs and supermarkets, besides the ever expanding segment of products for aesthetics, beauty and wellbeing. Today, individuals live more and, therefore, need to buy more to maintain a healthy, capable and productive body as per the logic of capitalism. Promoting a healthy life and stimulating the workforce are narrative devices that advertising resorts to and that support ideological parameters of the present time. Media discourse turns to issues that agree with current standards, especially, those idealized by the market. The diversification and expansion of production has as a necessary counterpart the intensifying consumption. That explains the emphasis of advertising messages on the idea of youth as an all-embracing and ever more elastic category that compresses childhood and postpones maturity. Unlike other age groups, the ideal of youth is associated to productivity, influence and efficiency. The market promises a wide range of choices to young consumers. Hence, they are important mediators of consumption practices in their families (Rocha \& Pereira, 2009).

Advertising activates an essential communicative dimension for the contemporary subject by producing discourses about goods and people around the dominant themes of the moment for the specific contexts of each social group. Ads trigger relational mechanisms capable of defining parameters of values, positions and interpretations on the meanings of products and those who buy them. Advertising narratives not only fulfill the most evident purpose of selling products, but they are also important devices for categorizing social actors. The act of consuming, or refusing to consume, products and services elicits hierarchies in collective imagination. Thus, objects transcend functionalities or utilities and carry multiple subjective correspondences, whether in social logic or in the logic of unstable and unconscious desire (Baudrillard, 1970/1998).

Individuals position themselves in communal life through the process of differentiation, which they do not experience as social imposition or subjection to codes of conduct, but as free choice and aspiration for distinctive adornments that elevate their status through consumption. Baudrillard (1970/1998) states that differentiation surpasses the realm of individuality, because the endless character of consumption is based on the dynamics of social relations. In his words:

\footnotetext{
${ }^{1}$ Source: http://www.planalto.gov.br/ccivil_03/leis/L9294.htm

${ }^{2}$ An international study shows the increase of cosmetic plastic surgeries across the globe. The United States, Brazil and Japan lead the world ranking of cosmetic procedures.Retrieved July 29, 2020, fromhttps://www.isaps.org/wpcontent/uploads/2018/11/2017-Global-Survey-Press-Release-br.pdf. 
To differentiate oneself is always, by the same token, to bring into play the total order of differences, which is, from the first, the product of the total society and inevitably exceeds the scope of the individual. In the very act of scoring his points in the order of differences, each individual maintains that order, and therefore condemns himself only ever to occupy a relative position within it. Each individual experiences his differential social gains as absolute gains; he does not experience the structural constraint which means that positions change, but the order of differences remains. (Baudrillard, 1970/1998, p. 62)

If individuals considered only the use-value of goods, their needs would quickly be met. The expansion of consumption, however, shows quite the opposite with the acceleration of reasons to buy, ceaseless productivity and uninterrupted search for goods that renovate themselves - or just appear to do so - at each production cycle. Classification is decisive in the renovation of tastes, social positions, symbols of prestige, representations of authority, forms of micro-power, guaranteeing conspicuous, active and continuous consumption, as well as the unlimited dimension of the acquisition of goods. Differentiation leads consumers to refer to other symbols indefinitely and leaves them in a perpetual state of dissatisfaction.

According to Baudrillard (1970/1998), satisfaction or the lack thereof in modern-contemporary society concerns the relation between consumption and the notion of happiness or salvation. Such a notion is far from being inherent to the individual in a supposedly universal or natural search for personal fulfillment. Happiness is an ideological and historically built precept that derives from the "myth of Equality" instilled in modern-industrial societies (Baudrillard (1970/1998, p. 50). That myth founds the idea that happiness should be flaunted in visible criteria, in evident materialities. If productivity is the center of the social system, abundance acquired through the continuous and regular progress of production should ensure equal happiness to every citizen. The "myth of equality" suppresses historical rules that once differentiated social segments, making consumption the key path for accessing equality and, therefore, happiness. The egalitarian demand gives precedence to individualistic principles over collective ones. In its ideal form, the purpose of consumer society is to give total comfort to each of its members (Baudrillard (1970/1998).

Well-being can be measured by objects and signs of convenience. Everyone is the same is terms of possibilities for accessing the use-value of goods and their implicit satisfactions. Ideologically, consumption takes on a democratic potential, since it can serve all. Differentiation, however, is a common social practice (Lévi-Strauss, 1962/2020). Categories are created as a form of establishing limits and maintaining hierarchies or complimentary relations between the different positions and activities needed for a society to function.

Moreover, there is no equality without differentiation. Alterity gives rise to groups and their identity expressions. The apparent capitalist democracy masks the impossibility of social equality. Unequal distribution of wealth promotes different degrees of access to products in consumer society and, therefore, to the ideal of happiness. Abundance of production does not suppose equality of distribution. Imbalanced social order divides the whole in layers of privilege and subordination (Baudrillard, 1970/1998). Principles may set store by equality, but the structure maintains itself through elevating some to a superior status to others. Prominence is acquired through consumption, a system that attributes cultural values to objects that become signs of prestige and power.

Advertising, as an extensive prescription book of identities in contemporary capitalist society, disseminates ideals of happiness through its magical messages and images. Its narratives circulate models and validate consumer culture as responsible for the code that defines happiness and well-being. In this sense, advertising, and the media in general, conveys references that construct subjectivities and promote relationships among individuals themselves and between individuals and goods (Freire Filho, 2003). In consumption rituals, individuals are attracted to the magical world "inside" ads, where power relations do not exist and everyone attains happiness (Author, 1995).

Media discourses legitimize moral and ethical values that emerged and spread across different spheres of the social fabric (Freire Filho, 2007). In this way, advertising representations articulate meanings and offer elements for subjects to organize their perceptions about themselves, others and the cultural universe that surrounds them.

\section{References}

Baudrillard, J. (1998). The consumer society: Myths and structures (Chris Turner, Trans). London: Sage.(Original work published 1970)

Baudrillard, J. (2002). Significação da publicidade. In: L. Costa Lima (Ed.), Teoria da cultura de massa. Rio de Janeiro: Paz e Terra.

Campbell, C. (2018). The romantic ethic and the spirit of modern consumerism. London: Palgrave Macmillam. (Original work published in 1987) 
DaMatta, R. (1985). Prefácio. In: E. Rocha. Magia e capitalismo: um estudo antropológico da publicidade. São Paulo: Brasiliense.

DaMatta, R. (2011). Apresentação. In: A. Van Gennep. Os ritos de passagem. Petrópolis: Vozes.

Douglas, M. \&Isherwood, B. (1979). The world of goods: Towards an anthropology of consumption.London: Allen Lane.

Freire Filho, J. (2003). Mídia, consumo cultural e estilo de vida na pós-modernidade.ECO-PÓS, v.6, no 1, p. 72-97, 2003.

Freire Filho, J. (2007). Como ser uma adolescente liberada no novo milênio. In: J. Freire Filho (Ed.). Reinvenções da resistência juvenil:Os estudos culturais e as micropolíticas do cotidiano (p. 111-162). Rio de Janeiro: Mauad.

G1. (2019). Expectativa de vida sobe 5,5 anos no mundo entre 2000 e 2016, diz relatório da OMS. Retrieved July 30, 2020, from https://g1.globo.com/ciencia-e-saude/noticia/2019/04/04/expectativa-de-vida-sobe-55-anos-nomundo-entre-2000-e-2016-diz-relatorio-da-oms.ghtml.

Lévi-Strauss, C. (1964) Totemism (R. Needham). London: Merlin Press. (Original work published 1962)

Lévi-Strauss, C. (2020). Wild Thought: A new translation of La Pensée Sauvage (J. Mehlman \& J. Leavitt, Trans.). Chicago: The University of Chicago Press. (Original work published 1962)

Marx, K. (1977). The Capital: A critique of political economy (B. Fowkes, Trans.). New York: Vintage Books. (Original work published 1867)

Marx, K., \& Engels, F. (1992). The Communist Manifesto (S. Moore, Trans.). New York: Oxford University Press. (Original work published 1848)

McCracken, G. (1988).CultureandConsumption: new approaches to the symbolic character of consumer goods and activities.Bloomington and Indianapolis: Indiana University Press.

McKendrik, N.,Brewer, J.,\&Plumb, J. H. (1982). The birth of consumer society.London: Europa Publications Limited.

Miller, D. (1998). A theory of shopping. Ithaca, NY: Cornell University Press.

Miller, D. (2008). The comfort of things. Cambridge: Polity Press, 2008.

Morin, E. (1962).L'esprit du temps: Essai sur la culture de masse. Paris: Grasset.

Rocha, E. \&Pereira, C. (2009).Juventude e Consumo:Um estudo sobre a comunicação na cultura contemporânea. Rio de Janeiro: Mauad X.

Simmel, G. (1957).Fashion. The American Journal of Sociology, LXII (6), 541-558.(Original work published 1904)

Trindade, E.,\&Perez, C. (2014). Os rituais de consumo como dispositivos midiáticos para a construção de vínculos entre marcas e consumidores. ALCEU, 15(29), 157-171.

Veblen, T. (2007). The theory of leisure class. Oxford: Oxford University Press. (Original work published 1899)

United Nations, Department of Economic and Social Affairs, Population Division. (2019). World population prospects2019: Highlights. Retrieved from https://population.un.org/wpp/Publications/Files/WPP2019_Highlights.pdf

Wagner, R. (1975).The invention of culture. São Paulo: Cosac Naify, 2010 [1975].

Williams, R. (1982).Dream worlds: Mass consumption in late nineteenth century France. Los Angeles: University of California Press. 